\title{
sciendo
}

\section{AN OPTIMIZED METHOD OF RNA ISOLATION FROM GOAT MILK SOMATIC CELLS FOR TRANSCRIPTOMIC ANALYSIS*}

\author{
Joanna Pławińska-Czarnak ${ }^{1 \bullet}$, Joanna Zarzyńska ${ }^{1}$ Janusz Bogdan ${ }^{1}$, Alicja Majewska², \\ Marek Karwański ${ }^{3}$, Magdalena Kizerwetter-Świda ${ }^{4}$, Jarosław Kaba ${ }^{5}$, Krzysztof Anusz, \\ Emilia Bagnicka $^{6}$
}

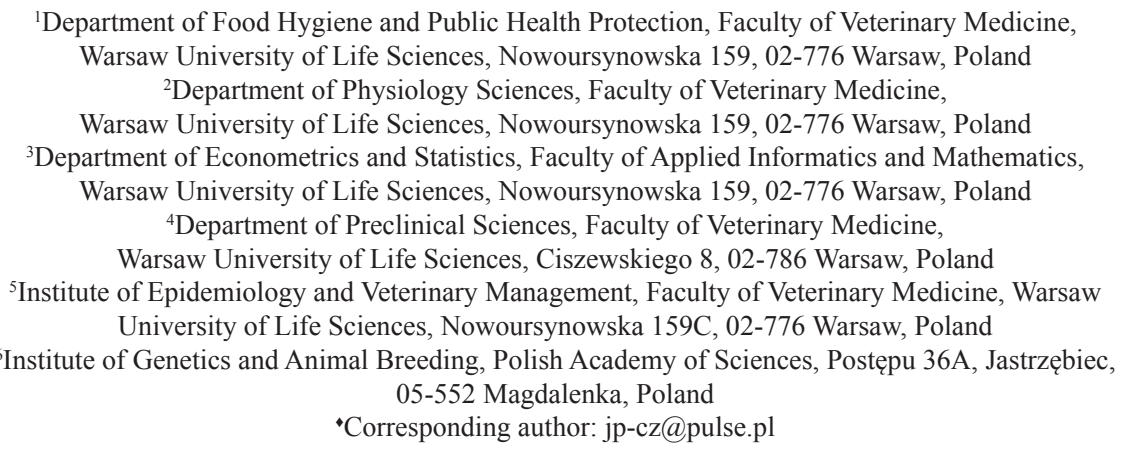

\begin{abstract}
The goat (Capra hircus) is a perfect animal model for analyzing the transcriptome of milk somatic cells (MSCs), as sufficient numbers of somatic cells in goat milk, i.e., exfoliated epithelial cells, can be obtained using noninvasive methods. RNA integrity and purity are the first and most important parameters qualifying samples for transcriptomic tests and next-generation sequencing, as RNA quality influences experimental results. The aim of this study was to optimize a method for obtaining high-quality RNA from goat MSCs, irrespective of effects like breed, lactation stage, health status (e.g., with or without small ruminant lentivirus [SRLV] infection), or number of somatic cells. Milk samples were obtained from goats of two Polish breeds in various lactation stages and in different parities, and from goats infected and not infected with SRLV. Altogether, 412 MSC samples were examined: 206 using method A with fenozol and 206 using method B with QIAzol. Though the overall purity (measured as absorbance ratios at $260 \mathrm{~nm} / 280 \mathrm{~nm}$ and $260 \mathrm{~nm} / 230 \mathrm{~nm}$ ) of the RNA material was comparable, the average yield of RNA isolated using method A was 11.9 $\mu \mathrm{g}$, while method B's average yield was $29.9 \mu \mathrm{g}$. Moreover, method B resulted in good quality RNA suitable for transcriptome analysis. Results were confirmed by RT-qPCR, using $18 S r R N A$ and $R P L P 0$ as the reference genes. The application of our modified treatment method was successful in obtaining high-integrity samples for transcriptomic or next-generation sequencing analysis. Using a $400 \mathrm{~mL}$ milk sample cooled in ice directly after milking, securing the cooling chain process from
\end{abstract}

\footnotetext{
*Work financed by The National Science Centre (NCN) Poland, project no. 2011/03/B/NZ6/03711.
} 
milking to MSC isolation, and applying method B to isolate RNA, we obtained good RNA quality irrespective of the goats' breed, lactation stage, parity, milk yield, SRLV infection, and even milk yield and number of somatic cells in milk.

Key words: goat, milk somatic cells, RNA isolation, transcriptomic analysis, RT-qPCR

The most widely used methods for examining the transcriptomic profile of an organism are hybridization-based microarray, next-generation sequencing technologies, and RNA-Seq. These methods are used to study the entire landscape in one assay.

The results of transcriptome analysis are widely used to discover novel disease subtypes, develop new diagnostic tools, and identify underlying mechanisms of disease or drug response (Coombes et al., 2004; Narrandes and Xu, 2018; Reisberg et al., 2018). The isolation of high-quality RNA is very important for successful gene expression analysis. The applicability of the isolated RNA in transcriptome analysis is determined by quality, purity, integrity and quantity.

Using NanoDrop technology, we can analyze the purity of RNA, while using the Agilent Bioanalyzer instrument RNA quality (RNA integrity number - RIN). RIN indicates the integrity of total RNA samples based on the entire electrophoretic trace of the RNA sample, including RNA degradation products (Schroeder et al., 2006; Majewska et al., 2019). The quality of RNA depends, among other factors, on the type of sampled tissue (Samadani et al., 2015). Some tissues, such as breasts, can have high fat content and low cell count, while others, like liver samples, can have high cell density but also be very fibrous (Peirson and Butler, 2007). Tissues such as those from lungs and liver are characterized by low RNA integrity because they are susceptible to faster RNA degradation by high levels of nucleases (Brown et al., 2018). Therefore, it is not recommended to use a universal extraction procedure for all tissue types (Peirson and Butler, 2007). Brown et al. (2018) compared five different commercial kits for isolating RNA from brain, lung, and liver tissues and clearly showed that not all RNA isolation kits can be used to the same effect for all tissues. When planning for gene expression analysis, one should remember proper procedures for sampling and protecting against RNA degradation and should select the appropriate isolation kit for the type of tissue or cells.

Caprine arthritis encephalitis (CAE) caused by small ruminant lentivirus (SRLV) is a disease that develops in various forms in adult goats, with symptoms such as arthritis, mastitis, and progressive weight loss, while in goat kids, its primary symptom is neuropathy. Our long-term study on SRLV infection in a goat herd revealed an increase in the number of milk somatic cells (MSCs) in milk from SRLV-infected goats compared to healthy goats in the first stage of infection (Pławińska-Czarnak et al., 2014).

The aim of this study was to develop a method to obtain high-quality RNA from goat MSCs irrespective of goats' breed, lactation stage, parity, milk yield, SRLV infection, and even milk yield and number of somatic cells in milk. 


\section{Material and methods}

\section{Animals}

The study was conducted on 24 dairy goats of two breeds, Polish White Improved and Polish Fawn Improved (PWI and PFI, respectively), which were selected from 50 goats maintained at a goat farm in Central Poland. The average milk yield in the herd during 280 days of lactation was approximately $800 \mathrm{~kg}$, with $3.35 \%$ of it being fat and 3.20\% of it being total protein. Goats were kept in a loose barn, milked mechanically twice a day, and fed according to the INRA system (Kowalski, 2009). The diet consisted of corn silage, wilted grass silage, and concentrates, supplemented with a mineral and vitamin mixture. Water was available ad libitum. All animals were checked for symptoms of clinical mastitis on a daily basis and only healthy animals were included in the study. The goats that qualified for the project had no udder diseases, were of both breeds, and were either healthy $(\mathrm{N}=12)$ or infected by SRLV (N=12), which causes CAE. Pławińska-Czarnak et al. (2014) had analyzed the impact of SRLV infection on milk yield previously.

\section{Milk sampling and microbiological analysis}

Goat milk samples were collected four times during lactation (on the 10th, 70th, 150th, and 230th day of lactation). The samples were collected from goats free of clinical mastitis during the morning milking. Prior to sampling, teats were washed and disinfected as per standard routine procedures.

To check the health of the mammary gland, all milk samples were microbiologically screened. The samples of "first milk" $(100 \mu \mathrm{L})$ were streaked on Columbia agar supplemented with 5\% sheep blood (bioMérieux, Craponne, France). Plates were incubated at $37^{\circ} \mathrm{C}$ for $48 \mathrm{~h}$. Isolated pathogens were identified using VITEK 2 equipment (bioMérieux, Craponne, France). Milk samples with negative results from bacteriological tests were subjected to further testing.

\section{MSC isolation}

After the pre-dipping, milk was taken and stored in sterile glass containers. Glass milk containers, milk centrifugation containers, and spatulas for fat collection underwent DNase and RNase inactivation procedures. Cleaned and autoclaved glass containers were heat-treated at $240^{\circ} \mathrm{C}$ for $4 \mathrm{~h}$, while plastic containers for milk centrifugation and spatulas were cleaned, sterilized, and additionally treated with RNaseZap ${ }^{\circledR}$ RNase Decontamination Solution (Ambion, Europe, UK), according to the manufacturer's recommendations. Other disposable plastics used (e.g., automatic pipette extensions of various volumes, ep Dualfilter T.I.P.S., Eppendorf, Germany) were marked on their packaging as DNase/RNase-free. Due to the great variety of MSC abundance in goat milk, depending on the parity and stage of lactation, the initial milk centrifugation was performed in several volume variations to determine the most suitable amount of cell sediment. We started with 1 liter of milk and then, in the subsequent analyses, we checked other volumes of milk samples $(500 \mathrm{~mL}$, $400 \mathrm{~mL}, 200 \mathrm{~mL}$, and $50 \mathrm{~mL}$ ). Due to the lack of any commercial kit dedicated to isolating RNA from MSCs, the MSCs were treated as a tissue since they contain 
a great variety of milk compounds and numerous enzymes. We empirically determined $50 \mathrm{~g}$ of MSC for RNA isolation to provide optimum results.

Various parameters of somatic cell centrifugation and rinsing were examined: milk temperature, centrifugation time, and centrifugation temperature.

1. Milk (without cooling) was centrifuged at room temperature no sooner than $4 \mathrm{~h}$ after milking.

2. Milk was stored in ice and centrifuged at $4^{\circ} \mathrm{C}$ no sooner than $2 \mathrm{~h}$ after milking.

3. Milk was stored in ice and centrifuged at $4^{\circ} \mathrm{C}$ immediately after milking.

The milk sample was centrifuged with a final concentration of $0.5 \mathrm{mM}$ EDTA (Boutinaud et al., 2002) (Ethylenediaminetetraacetic acid solution, BioUltra; for molecular biology, $\mathrm{pH} 8.0, \sim 0.5 \mathrm{M}$ in $\mathrm{H}_{2} \mathrm{O}$; Sigma-Aldrich, Poland); the centrifugation was performed at $4^{\circ} \mathrm{C}$ at $1700 \times \mathrm{g}$ for $25 \mathrm{~min}$ with an Eppendorf $5810 \mathrm{R}$ centrifuge (container volume $400 \mathrm{~mL}$, Eppendorf, Germany). The fat layer was removed with a sterile spatula, the milk was removed, and the obtained cell sediment was rinsed twice using phosphate-buffered saline (PBS; pH 7.45; Gibco ${ }^{\mathrm{TM}}$ Invitrogen Corporation, UK) with EDTA $(0.5 \mathrm{mM})$. The initial rinse was a cautious removal of sediment from the container bottom, using $45 \mathrm{~mL}$ of PBS-EDTA (the sediment cannot be scratched off since this might cause mechanical damage to the cells and RNA degradation). Subsequently, $22.5 \mathrm{~mL}$ of each prepared sediment was poured into two sterile $50 \mathrm{~mL}$ Falcon ${ }^{\circledR}$ test tubes (Becton Dickinson and Company, USA), and they were centrifuged at $1700 \times \mathrm{g}$ for $15 \mathrm{~min}$. After removing supernatant, a $20 \mathrm{~mL}$ of PBS-EDTA was added. After the last centrifugation, the cell sediment was rinsed with $5 \mathrm{~mL}$ of PBS and centrifuged at $2000 \times \mathrm{g}$ for $5 \mathrm{~min}$. After removal of PBS, the cell pellet was mixed with the cell lysis reagent and RNA stabilization. Samples prepared in this manner (two from the original milk sample) were stored at $-80^{\circ} \mathrm{C}$ until further RNA extraction. All buffers used for rinsing were sterile and stored at $4^{\circ} \mathrm{C}$.

\section{RNA isolation from MSCs}

Two commercially available kits for total RNA isolation were compared on stanchions using fenozol (method A) and QIAzol (method B). Regardless of the applied isolation kit, sterile PCR clean extensions with filters pipette tips (ep Dualfilter T.I.P.S., Eppendorf, Germany - originally contained in boxes) were used each time.

RNA isolation with method A was performed using the Total RNA Mini (A\&A Biotechnology, Poland), according to the manufacturer's instructions. RNA isolation with method B was performed using the RNeasy Lipid Tissue Mini Kit (Qiagen, Germany), according to the manufacturer's instructions. The option of DNase I digestion (RNase-Free DNase Set, Qiagen, Germany) was applied. The purified RNA was kept in test tubes at $-20^{\circ} \mathrm{C}$ until further analyses.

\section{Assessment of RNA purity and integrity}

All RNA samples were examined for their concentration, purity, and integrity.

The purity of RNA and abundance were determined for each sample using a NanoDrop spectrophotometer (Thermo Fisher Scientific, USA) to determine the optical density (OD) A260/A280 and A260/A230 ratios and RNA concentration in $\mathrm{ng} / \mu \mathrm{L}$. 
The integrity of RNA samples was assayed by the Agilent Bioanalyzer 2100 (Agilent Technologies, USA) using the Agilent RNA 6000 Nano Kit, and data were generated as an electropherogram. RIN was calculated by Agilent Software Expert. The concentration of RNA in the samples tested with the Bioanalyzer did not exceed $500 \mathrm{ng} / \mu \mathrm{L}$; samples with concentrations higher than $500 \mathrm{ng} / \mu \mathrm{L}$ were diluted with RNase-Free Water (Qiagen, Germany) for this analysis.

\section{Reverse transcription quantitative polymerase chain reaction (RT-qPCR)}

To confirm the effect of RNA quality on the results of gene expression analysis, a PCR reaction was performed for the reference genes $18 \mathrm{~S}$ ribosomal RNA (18S $r R N A$, GenBank accession number: DQ_066896.1, Primers (5'-3'): forward: CAAATTACCCACTCCCGACCC; reverse: AATGGATCCTCGCGGAAGG, amplicon size 114 bp) and Ribosomal Protein Large, P0 (RPLP0, NM_001012682.1, Primers $\left(5^{\prime}-3^{\prime}\right)$ : forward: CAACCCTGAAGTGCTTGACAT; reverse: AGGCAGATGGATCAGCCA, amplicon size 227 bp) (Finot et al., 2011; Pławińska-Czarnak et al., 2019). Total RNA was reversely transcribed to first strand complementary DNA (cDNA) using the High-Capacity cDNA Reverse Transcription Kit (Applied Biosystems, USA). All analyses were performed on individual samples using SYBR Select Master Mix (Applied Biosystems, USA) on a Stratagene Mx3005P (Agilent Technologies, USA) quantitative PCR instrument for RT-PCR, following the manufacturer's protocol. Real-time PCR was run using four step cycles: cycle 1 at $95^{\circ} \mathrm{C}$ for two min for polymerase activation, followed by 40 amplification cycles at $95^{\circ} \mathrm{C}$ for 15 seconds to allow denaturation (cycle 2), then at $58^{\circ} \mathrm{C}$ for 15 seconds for annealing (cycle 3 ), and finally at $72^{\circ} \mathrm{C}$ for one minute to allow for extension of DNA polymerase (cycle 4). The relative expression of the reference genes was quantified as the mean of triplicate measurements for each biological sample $(\mathrm{N}=22$ for each method A and B). Results were calculated using the $2^{-\Delta \mathrm{CT}}$ method, and unpaired t-test (Livak and Schmittgen, 2001).

\section{Statistical analysis and methods}

The mean and standard deviations of RIN, RNA concentration, and the A260/A280 and A260/A230 reading were calculated for each isolation method.

The preliminary dependence analysis was carried out between targets A260/A280, A260/A230, RIN, and effects, such as goat breed (PWI, PFI), SRLV infection (SRLV-infected, SRLV-free), lactation, milk yield, and MSC abundance. The monomial parameters were: goat breed (PWI, PFI), SRLV infection (SRLV-infected, SRLV-free), and parity (1st, 2nd, $\geq 3$ rd lactation). The polynomial parameters were: milk yield in the morning milking, the number of MSCs (the variability of which could be noted in the examined herd of goats), and RNA concentration in $\mathrm{ng} / \mu \mathrm{L}$. These polynomial parameters were subdivided into quartiles with the same number of samples in each to eliminate the impact of the number of parameter groups on the values of A260/A280 and A260/A230 in RNA isolation methods A and B.

The initial part of the statistical analysis consisted of calculating and presenting descriptive statistics of effects and target values. The main analysis was carried out using generalized linear mixed models (GLMMs). The final model had a logarithmic 
link function with Gaussian distribution and a random coefficient blocking effect. The variable selection was carried out according to Akaike information criterion (AIC). The Laplace approximation method was used for estimating the model parameters. The model was used to examine and test effects and their interactions. All analyses were conducted in the statistical package SAS/STAT (rel.14.1).

\section{Results}

With respect to the repeatability of the cell sediment abundance and the quality of the RNA obtained from the MSCs, the best results were achieved from a volume of $400 \mathrm{~mL}$ of goat milk cooled in ice directly after milking. From this volume of milk, we obtained two samples of MSC sediments ranging from $70 \mathrm{mg} \pm 20$ at various lactation stages. The somatic cell isolation time from 12 milk samples did not exceed $4 \mathrm{~h}$, beginning at the point of milking and lasting until the MSCs were secured by the lysis buffer. The average yield of RNA isolated from that milk volume by method A was $11.9 \mu \mathrm{g}$, whereas by method $\mathrm{B}$, the average yield was $29.9 \mu \mathrm{g}(\mathrm{P} \leq 0,01)$.

\section{RNA quality}

\section{OD ratios}

For both isolation methods, samples with average OD values of A260/A280 and A260/A230 were obtained. The OD values of A260/A280 were $2.04 \pm 0.014$ for method A and $2.04 \pm 0.012$ for method B. The OD values of A260/A230 were $2.01 \pm 0.026$ for method A and $1.98 \pm 0.027$ for method B. No differences for A260/ A280 and A260/A230 OD values were found for either monomial or polynomial variables.

\section{RNA integrity number (RIN)}

Statistics for RIN according to different parameters and the means, standard errors, and 95\% confidence interval are presented in Tables 1.

The difference between average RIN in method A $(3.99 \pm 0.184)$ and $\mathrm{B}$ $(7.49 \pm 0.152)(\mathrm{P}<0.0001)$ was found. The percentage of samples with a RIN $\geq 7.0$ isolated using method A was $6.42 \%$ and for method B, it was $86.4 \%$ of all samples tested.

For both methods of RNA isolation, the variables (such as goat breed, SRLV infection or its lack, or parity) had no statistically relevant impact on RIN (Table 1). However, a general comparison analysis of parameters, such as milk yield, milk somatic cell count (SCC), and RNA concentration, between the two RNA isolation methods revealed a significant difference in the quality of the obtained RNA. During the experiment, the milk yield ranged from 0.2 to $3.6 \mathrm{~L} /$ day. An analysis of the goat milk yield in the quartile samples revealed that an average RIN of $3.92 \pm 0.258$ was achieved for method A, while in method B, the average RIN was $7.48 \pm 0.249$. Detailed variations and the mean statistical error margin are presented in Table 1. 


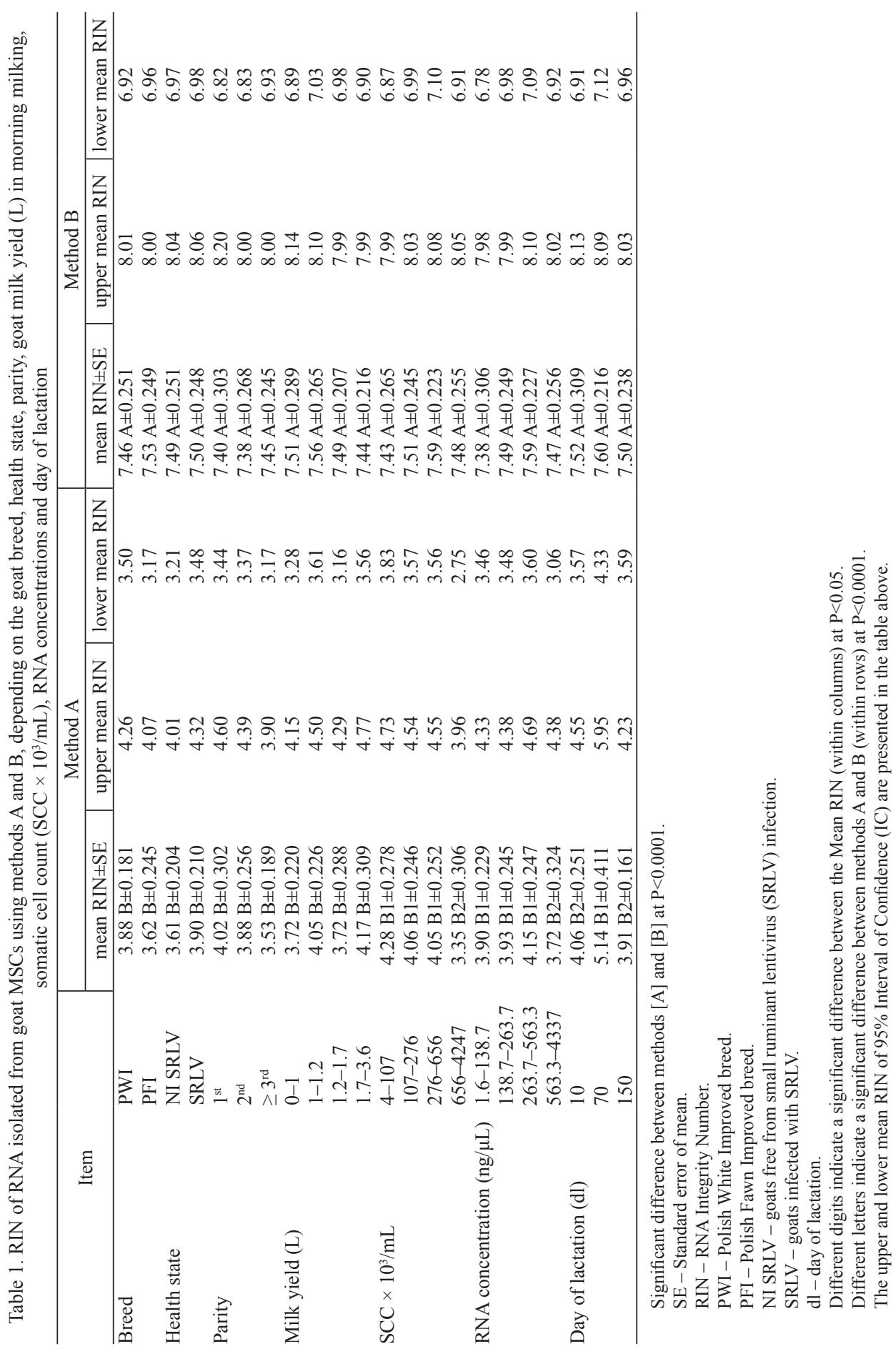


The highest RINs were achieved at SCC $\leq 107 \times 10^{3} / \mathrm{mL}$ of milk $(\mathrm{RIN}=4.28 \pm$ 0.278 ) for method $A$. There was a significant decrease in RNA quality and integrity with an increase of the SCC $>656 \times 10^{3}$ in $1 \mathrm{~mL}$ of milk using method A (average $\mathrm{RIN}=3.35 \pm 0.306$ ), thus, an increase in SCC had a remarkable impact on RIN value in this method. Exfoliated cells are easily damaged, and RNase present in milk (Ben Chedly et al., 2010; Dalaly et al., 1980) accelerate RNA degradation. In method B, a slight decrease in RIN value at SCC $\geq 276 \times 10^{3} / \mathrm{mL}$ was statistically insignificant. The average RINs for SCC ranges are presented in Table 1. With an increase of somatic cells in $1 \mathrm{~mL}$ of milk, an increase in the isolated RNA concentration was noted. Using method A, a relevant RIN decrease with higher RNA concentration (RNA > $563.3 \mathrm{ng} / \mu \mathrm{L}$ ) was reported.

For method A of RNA isolation, RIN also changed with the stage of lactation. The highest quality RNA was obtained at $70 \mathrm{dl}$ and the lowest at $230 \mathrm{dl}$. In method $\mathrm{B}$ no decrease in RNA integrity with the passing of days within the lactation was reported. The differences in mean RIN values between the RNA concentration are presented in Table 1.

\section{$R T-q P C R$}

In a qPCR reaction, the quantification cycle value is defined as the number of cycles required for the fluorescent signal to exceed the background, referred as the threshold cycle (Ct) or crossing point (Cp) (Kuang et al., 2018). Results of the expression analysis of the $18 S$ rRNA and RPLPO genes demonstrated that the highquality RNA $(\mathrm{RIN}>7.5)$ resulted in a high expression level (low $\mathrm{Cp}$ ), while the low-quality RNA (RIN < 4.0) resulted in a low expression level (high $\mathrm{Cp}$ ). The correlation between the RNA quality when samples from method B were compared to samples from method A were calculated using the $2^{-\Delta \mathrm{CT}}$ method, and unpaired t-test (Livak and Schmittgen, 2001). The difference was significant for both reference genes (P-value $<0.0001$ ). The standard error of the mean (SE) in method A for 18S RNA was $0.0002002 \pm 2.125 \mathrm{e}-005$ and for RPLP0 was $2.02 \mathrm{e}-008 \pm 6.094 \mathrm{e}-009$. In method B $0.0009742 \pm 6.092 \mathrm{e}-005$ and $1.797 \mathrm{e}-007 \pm 1.251 \mathrm{e}-008$ respectively.

\section{Discussion}

The number of somatic cells in goat milk and their composition change not only during mammary gland inflammation but also during lactation, with the number of lactation, and during estrus. Moreover, this number also depends on the method of milking, the structure of the udder and teats, and herd management (Bagnicka et al., 2011). It should also be noted that as the days in the lactation period pass, the number of late apoptotic cells with degraded RNA increases (Capuco et al., 2001). RNA degradation also continues after cell death, and many extremely resistant RNases are also secreted outside the cell (Fordyce et al., 2013), thus RNA also degrades during storage and handling. RNA degradation is a known disruptive factor for all methods of quantifying RNA-based gene expression, such as expression microarrays (Reiman 
et al., 2017). Sanchez-Macias et al. (2010) reported that with the passage of time after sampling and with an increase in milk temperature, the number of detected somatic cells decreases. However, MSC isolation and RNA isolation procedures should not affect the quality of the derived RNA, therefore the isolation conditions have to be optimal. This is especially important for samples taken in field conditions, as there is likely to be some distance between the goat herd and laboratory.

Unfortunately, there is no single best method of MSC isolation for all dairy animal species, perhaps because the number of cells and its composition varies a lot between them (Bagnicka et al., 2011; Wickramasinghe et al., 2012; Cieslak et al., 2015; Suárez-Vega et al., 2015). It is also extremely difficult to isolate high-quality RNA - first and foremost, RNA with high integrity - from MSCs. This difficulty is in part due to the fact that MSCs contain large numbers of various enzymes, including RNases (Li et al., 2014). In the healthy mammary gland, approximately 50\% of goat MSCs are exfoliated epithelial cells. These cells are very delicate and are often at different phases of apoptosis, such that all mechanical manipulations damage them and lead to RNA degradation. The effects of RNA degradation following cell death and tissue isolation are omnipresent and can rapidly obscure inter-individual differences in gene expression: this is a recognized source of uncertainty (Gallego Romero et al., 2014). The key factor is the quantity of the milk sample from which the MSCs are isolated. Ben Chedly et al. (2011) derived MSCs from $1.4 \mathrm{~kg}$ of goat milk. This is a fairly large amount and is thus not always obtainable from certain breeds, from young animals, or from animals at various lactation stages. Our study showed that $400 \mathrm{~mL}$ of cooled goat milk is entirely sufficient to derive a satisfactory number of MSCs for analysis. Furthermore, this volume of milk is easily obtainable across goat breeds, parities, and lactation stages.

To determine the applicability of RNA samples for use in further studies with RTqPCR, as well as other array methods, such as gene expression microarrays or RNASeq, it is vital to determine basic parameters, such as quality, purity, and quantity of the RNA. In our studies, both of the RNA isolation methods we tested (A and B) produced correct values for A260/A280 and A260/A230, indicating that the derived RNA was free from chemical or protein contamination. Using method B, we noticed a slight decrease in the A260/A230 absorbance, below level 2. Cicinnati et al. (2008), who also applied kits of the same manufacturer and found a similar result, suggested that this decrease may be due to the presence of guanidine salts, though these would not be abundant enough to distort the accuracy of genomic arrays. Though RNA isolated using both methods exhibited comparable purity, the purity did not correlate with high RIN value in method A. Badrul et al. (2011) and Li et al. (2016) showed that correct values of A260/A280 and A260/A230 do not determine RIN value, which is why checking RIN values is crucial for gene expression analyses.

There are many different commercial kits available to extract total RNA from various tissues and cells other than milk. Numerous reports have indicated differences in extraction efficiency from the same tissues depending on the method used for RNA isolation. This result was demonstrated by Sellin Jeffries et al. (2014), who isolated RNA from spleen, blood, kidney, and embryo tissues; by Dastgheib et al. (2014) with pancreatic tissue; Kolijn et al. (2016) with prostate tissue; and Norollahi 
et al. (2018) with breast and gastric cancer. Dudemaine et al. (2017) compared five commercial kits used to extract total RNA, including miRNA, using three cow's milk fractions (fat, whey, and somatic cells) and obtained different RIN results depending on the set and milk fraction.

Both methods analyzed in our study produced a high average RNA concentration level $(\mathrm{A}=250 \mathrm{ng} / \mu \mathrm{L} ; \mathrm{B}=707 \mathrm{ng} / \mu \mathrm{L})$, which is sufficient for microarray tests, for result assessments using RT-qPCR, or for other tests that use RNA and that require numerous repetitions.

Our study revealed that the quantity of RNA increases in subsequent parities and during stages of the lactation period. This is a direct effect of the increase in goat somatic cells that takes place over the course of the lactation period and in subsequent parities (Boutinaud and Jammes, 2002). This factor should be considered when planning mammary gland experiments that use milk samples as research material.

The choice of the RNA isolation method is very important when planning genomic RNA-based studies. Thompson et al. (2007) showed that RNA samples with a RIN $\leq 7$ decrease microarray specificity and sensitivity, whereas other authors (Boutinaud et al., 2013; Brenaut et al., 2014; Suárez-Vega et al., 2015; Pławińska-Czarnak et al., 2019) stated that only RINs $\geq 7.5$ are useful for obtaining high-quality gene expression microarray data. The minimum acceptable RIN value depends on the type of analysis to be performed. For example, in several studies, RNAs with RIN values $\geq 5-5.5$ were discovered to provide an adequate matrix for qPCR reactions in cases where the amplicon length did not exceed 200 bp (Fleige and Pfafl, 2006; Schroeder et al., 2006; Sellin Jeffries et al., 2014). However, most of the studies are conducted only on samples with RIN $>7$ (Toral et al., 2016).

The use of method B for isolating RNA from MSCs allowed obtaining a much higher number of results with a RIN $\geq 7.0$ ( $>86 \%$ of the total sample amount) from samples with miscellaneous MSC abundance. This finding reconfirms that method B should be the preferred method when isolating RNA from a material exhibiting much variability in cell number in a $1 \mathrm{~mL}$ volume, such as goat milk. The effective use of a kit dedicated to fatty tissues to isolate RNA from MSCs indicates the substantial impact of milk fat on RNA results, even when the fat is removed through sample centrifugation preceding the isolation of MSCs (Pławińska-Czarnak et al., 2019).

The RIN values achieved with method A did not produce results that qualified MSC-derived RNA samples for further arrays because the RNA was degraded. The results of the correlation between RNA quality (from method A and method B) and $\mathrm{Cp}$ in RT-qPCR fulfilled the expectations. This phenomenon was especially notable when the Cp was shifted towards higher cycle numbers using RNA with a RIN below 4.0. It should be remembered that degraded RNA may not give an accurate representation of gene expression (Kuang et al., 2018). Therefore, microarray studies need high-quality RNA to avoid the risk of false negative results.

Though this remark goes beyond the scope of this paper, it is worth mentioning that when RNA from nucleated blood cells is isolated using method A, the quality is not objectionable. In a previous study, we used method A to obtain high-integrity RNA, with the RIN value ranging from 8.0 to 9.9 (average RIN $=8.9$ ) from peripheral nuclear blood cells (Pławińska-Czarnak et al., 2019). Thus, method A can 
be successfully applied to isolate non-degraded RNA from tissues, such as blood or from cell lines, but not to isolate RNA from MSCs. These data confirm that the method of RNA isolation must be appropriate to the type of tissue.

The crucial factor for deriving high-quality RNA from MSCs is the way the milk sample is treated before and during the MSC isolation. Milk contains large amounts of various enzymes, including ribonuclease (Gupta and Mathur, 1989). Our research revealed that, similarly to sheep milk (Suárez-Vega et al., 2015), cooling the goat milk quickly after milking was of great importance, as was the temperature of centrifugation and of rinsing additives $\left(4^{\circ} \mathrm{C}\right)$. The best RNA sample quality was achieved when the milk was cooled in ice immediately after the milking and when the MSCs were isolated no later than $4 \mathrm{~h}$ from the point of milking. Thus, effective planning of laboratory work, especially when sampling is conducted in the field, plays a crucial role in obtaining high-quality RNA. These findings are consistent with those of Sanchez-Macias et al. (2010), who reported that with the passage of time and with an increase of milk temperature, the amount of detected somatic cells decreases.

The discussed results indicate that our protocol is successful in obtaining highintegrity RNA samples (high-quality RNA isolated in sufficient quantities, with maximum repeatability). Using a $400 \mathrm{~mL}$ milk sample, cooling the milk in ice immediately after milking, following MSC isolation procedures (within 4 hours after sampling), and applying method B to isolate RNA we obtained high quality RNA, irrespective of the goats' physiological variables, such as breed, lactation stage, parity, milk yield, SRLV infection, and even MSC abundance.

\section{Ethics Statement}

Warsaw University of Life Sciences Institutional Animal Care and Use Committee (IACUC) is a III Local Ethical Committee. All procedures were carried out in accordance with the guidelines of this committee. The III Local Ethical Committee approved this research, and the approval was presented as formal written decision No. 63/2012.

\section{References}

B adrul H.Y., Mc Lachlan G., Vret to u C., Colli e D. (2011). Optimising the quality and integrity of RNA samples from bronchial air way tissues. Asia Pac. J. Mol. Biol. Biotechnol., 19: 19-27.

Bagnicka E., Winnicka A., Jóźwik A., Rzewuska M., Strzałkowska N., Kościuczuk E., Prusak B., Kaba J., Horbańczuk J.O., Krzyżewski J. (2011). Relationship between somatic cell count and bacterial pathogens in goat milk. Small Rumin. Res., 100: 72-77.

B en Chedly H., B out inaud M., B ernier-Dodier P., Marnet P.G., Lac as se P. (2010). Disruption of cell junctions induces apoptosis and reduces synthetic activity in lactating goat mammary gland. J. Dairy Sci., 93: 2938-2951.

Ben Chedly H., Lacasse P., Marnet P., Komara M., Marion S., Boutinaud M. (2011). Use of milk epithelial cells to study regulation of cell activity and apoptosis during oncedaily milking in goats. Animal, 5: 572-579.

B o u t i n a u d M., J a m m e s H. (2002). Potential uses of milk epithelial cells: a review. Reprod. Nutr. Dev., 42: 133-147. 
B out in a d M., Rulquin H., K e i s l e r D.H., D j i a n e J., J a m m e s H. (2002). Use of somatic cells from goat milk for dynamic studies of gene expression in the mammary gland. J. Anim. Sci., 80: $1258-1269$.

B out in aud M., Galio L., Lollivier V., F in ot L., Wi art S., E s querré D., Devinoy E. (2013). Unilateral once daily milking locally induces differential gene expression in both mammary tissue and milk epithelial cells revealing mammary remodeling. Physiol. Genomics, 45: 973-985.

Brenaut P., Lefèvre L., Rau A., Laloë D., Pisoni G., Moroni P., B evilacqua C., Martin P. (2014). Contribution of mammary epithelial cells to the immune response during early stages of a bacterial infection to Staphylococcus aureus. Vet. Res., 45: 16.

B rown R., Ep is M.R., Horsham J.L., Kabir T.D., Richardson K.L., Le edman P.J. (2018). Total RNA extraction from tissues for microRNA and target gene expression analysis: not all kits are created equal. BMC Biotechnol., 18: 16.

Capuco A.V., Wood D.L., B aldw in R., McLeod K., P a a p e M.J. (2001). Mammary cell number, proliferation, and apoptosis during a bovine lactation: relation to milk production and effect of bST. J. Dairy Sci., 84: 2177-2187.

C i c innat i V.R., Shen Q., S ot ir op oulos G.C., Radtke A., Gerken G., B e c k e bau m S. (2008). Validation of putative reference genes for gene expression studies in human hepatocellular carcinoma using real-time quantitative RT-PCR. BMC Cancer, 8: 350.

Cieslak J., Mackowski M., Czyzak-Runowska G., Wojtowski J., Puppel K., Kuczynska B., Paw lak P. (2015). Screening for the most suitable reference genes for gene expression studies in equine milk somatic cells. PLoS ONE, 10(10): e0139688.

C o o m b e s B.K., H a r d w i d g e P.R., F in l a y B.B. (2004). Interpreting the host-pathogen dialogue through microarrays. Adv. Appl. Microbiol., 54: 291-331.

Dalaly B.K., Eitenmiller R.R., Friend B.A., Shahani K.M. (1980). Human milk ribonuclease. Biochim. Biophys. Acta, 65: 381-391.

Dastgheib S., Iraji e C., A s s a i R., Kooh peima F., Mokarram P. (2014). Optimization of RNA extraction from rat pancreatic tissue. Iran. J. Med. Sci., 39: 282-288.

Du d e ma in e P.L., F o men k y B., D u to it A., B éj a n in L., I b e a g h a - Aw e mu E.M. (2017). 341 Comparison of five commercial kits for total RNA isolation including microRNA from three bovine milk fractions. J. Anim. Sci., 95: 168-169.

Finot L., Marnet P.G., Dessauge F. (2011). Reference gene selection for quantitative real-time PCR normalization: application in the caprine mammary gland. Small Rumin. Res., 95: 20-26.

F le i g e S., P fa fl M.W. (2006). RNA integrity and the effect on the real-time qRT-PCR performance. Mol. Aspects Med., 27: 126-139.

Fordyce S.L., Kampmann M.-L., van Doorn N.L., Gilbert M.T.P. (2013). Long-term RNA persistence in postmortem contexts. Investig. Genet., 4: 7.

Galle g o Rom e ro I., P a i A.A., T ung J., Gil a d Y. (2014). RNA-seq: impact of RNA degradation on transcript quantification. BMC Biol., 12: 42.

Gupta N., Mathu r M.P. (1989). Level and distribution of ribonuclease in milk from different species. Indian J. Dairy Sci., 42: 547-549.

K o lij n K., G e e r t J.L., va n L e e n d e r s H. (2016). Comparison of RNA extraction kits and histological stains for laser capture microdissected prostate tissue. BMC Res. Not., 9: 7.

K o w a ls k i M. (2009). Standard of dairy goats' feeding. In: NRIAP-INRA, Standard of ruminants' feeding: nutrient value of French and domestic fodders for ruminants, Strzelecki (ed.) (in Polish). National Research Institute of Animal Production, Kraków, Poland, pp. 109-119.

Kuang J., Yan X., Genders A.J., Gran a t a C., B is ho p D.J. (2018). An overview of technical considerations when using quantitative real-time PCR analysis of gene expression in human exercise research. PLoS ONE, 13(5): e0196438.

Li R., Richoux N., B out in a d M., Martin P., G a gna ir e V. (2014). Role of somatic cells on dairy processes and products: a review. Dairy Sci. Technol., 94: 517-538.

Li R., Dudemaine P.L., Zhao X., Lei C., Ibeagha-Awemu E.M. (2016). Comparative analysis of the miRNome of bovine milk fat, whey and cells. PloS One, 11(4): e0154129.

Livak K.J, S chmittgen T.D. (2001). Analysis of relative gene expression data using real time quantitative PCR and the $2^{\Delta \Lambda} \mathrm{C}(\mathrm{T})$ method. Methods, 25: 402-408. 
Majewska A., Domoradzki T., Grzelkowska-Kowalczyk K. (2019). Transcriptomic profiling during myogenesis. Methods Mol. Biol., 1889: 127-168.

$\mathrm{N}$ a r r a n d e s S., X u W. (2018). Gene expression detection assay for cancer clinical use. J. Cancer, 9: $2249-2265$.

Norollahi S.A., Kokhaee P., Rashidy-Pour A., Hojati V., Norollahi S.E., Lari$\mathrm{j}$ a $\mathrm{ni}$ L.V., S a m a d a n A.A. (2018). Comparison of methods of RNA extraction from breast and gastric cancer tissues. Crescent J. Med. Biol. Sci., 5: 25-28.

P e ir s on S.N, B ut le r J.N. (2007). RNA extraction from mammalian tissues. Methods Mol. Biol., 362: 315-327.

Pławińska-Czarnak J., Bagnicka E., Kaba J., Bogdan J., Zarzyńska J. (2014). Analysis of the CAEV infection impact on the milk yield and milk SCC of Polish dairy goats. J. Microbiol. Biotech. Food Sci., 3: 39-42.

Pławińska-Czarnak J., Z arzyńska J., Majewska A., Jank M., Kaba J., B ogdan J., A nus z K., B a gnicka E. (2019). Selected tissues of two Polish goat breeds do not differ on genomic level. Anim. Sci. Pap. Rep., 37: 53-64.

R e i m a n M., L a a n M., Rul1 K., Sõ b e r S. (2017). Effects of RNA integrity on transcript quantification by total RNA sequencing of clinically collected human placental samples. FASEB J., 31: 3298-3308.

Reisberg S., Krebs K., Lepamets M., Kals M., Mägi R., Metsalu K., Lauschke V.M., Vilo J., Mila ni L. (2018). Translating genotype data of 44,000 biobank participants into clinical pharmacogenetic recommendations: challenges and solutions. Genet. Med., 21: 13451354.

Samadani A.A., Nikbakhsh N., Fattahi S., Pourbagher R., Aghajanpour M i r S.M., Mousavi Kani N., Abedian Z., Akhavan-Niaki H. (2015). RNA extraction from animal and human's cancerous tissues: does tissue matter? Int. J. Mol. Cel. Med., 4: 54-59.

Sanchez-Macias D., Castro N., Moreno-Indias I., Morales-delaNuez A., B rigg s H., Ca pote J., A rg ü ello A. (2010). The effects of storage temperature on goat milk somatic cell count using the DeLaval counter. Trop. Anim. Health Prod., 42: 1317-1320.

Schroeder A., Mueller O., S tocker S., S alowsky R., Leiber M., Gassmann M., Lightfoot S., Menzel W., Granzow M., Ragg T. (2006). The RIN: an RNA integrity number for assigning integrity values to RNA measurements. BMC Mol. Biol., 7: 3.

Sellin Jeffries M.K., Kis s A.J., S mith A.W., Or is J.T. (2014). A comparison of commercially-available automated and manual extraction kits for the isolation of total RNA from small tissue samples. BMC Biotechnol., 14: 94.

S uárez-Veg a A.,Gut iérrez-Gil B.,K lop p C.,Robert - Gran i e C.,Tos ser-K lopp G., A rran z J.J. (2015). Characterization and comparative analysis of the milk transcriptome in two dairy sheep breeds using RNA sequencing. Sci. Rep., 5: 18399.

Thom ps on K.L., P in e P.S., R o s en zw e ig B.A., Turpaz Y., R e ti e f J. (2007). Characterization of the effect of sample quality on high density oligonucleotide microarray data using progressively degraded rat liver RNA. BMC Biotechnol., 7: 57.

Toral P.G., Hervás G., S uáre z-Veg a A., A rranz J.J., Frutos P. (2016). Isolation of RNA from milk somatic cells as an alternative to biopsies of mammary tissue for nutrigenomic studies in dairy ewes. J. Dairy Sci., 99: 8461-8471.

Wickram as inghe S., Rin con G., I s las - Tre jo A., M edran o J.F. (2012). Transcriptional profiling of bovine milk using RNA sequencing. BMC Genomics, 13: 45.

Received: 14 X 2018

Accepted: 19 III 2019 